\title{
L-Citrulline increases nitric oxide and improves control in obese asthmatics
}

\author{
Fernando Holguin, ${ }^{1}$ Hartmut Grasemann, ${ }^{2}$ Sunita Sharma, ${ }^{1}$ Daniel Winnica, ${ }^{1}$ Karen Wasil, ${ }^{1}$ \\ Vong Smith, ${ }^{1}$ Margaret H. Cruse, ${ }^{1}$ Nancy Perez, ${ }^{1}$ Erika Coleman, ${ }^{1}$ Timothy J. Scialla, ${ }^{3}$ \\ and Loretta C. Que ${ }^{3}$ \\ 'Department of Medicine, University of Colorado Medical School, Aurora, Colorado, USA. ²Department of Pediatrics, \\ Hospital for Sick Children, Toronto, Ontario, Canada. ${ }^{3}$ Department of Medicine, Duke University School of Medicine, \\ Durham, North Carolina, USA.
}

BACKGROUND. The airways of obese asthmatics have been shown to be NO deficient, and this contributes to airway dysfunction and reduced response to inhaled corticosteroids. In cultured airway epithelial cells, L-citrulline, a precursor of L-arginine recycling and NO formation, has been shown to prevent asymmetric dimethyl arginine-mediated (ADMA-mediated) NO synthase (NOS2) uncoupling, restoring NO and reducing oxidative stress.

METHODS. In a proof-of-concept, open-label pilot study in which participants were analyzed before and after treatment, we hypothesized that $15 \mathrm{~g} / \mathrm{d}$ L-citrulline for 2 weeks would (a) increase the fractional excretion of NO (FeNO), (b) improve asthma control, and (c) improve lung function. To this end, we recruited obese (BMI >30) asthmatics on controller therapy, with a baseline FeNO of $\leq 30 \mathrm{ppb}$ from the University of Colorado Medical Center and Duke University Health System.

RESULTS. A total of 41 subjects with an average FeNO of $17 \mathrm{ppb}(95 \% \mathrm{Cl}, 15-19)$ and poorly controlled asthma (average asthma control questionnaire [ACQ] 1.5 [95\% Cl, 1.2-1.8]) completed the study. Compared with baseline, L-citrulline increased whereas ADMA and arginase concentration did not (values represent the mean $\Delta$ and $95 \% \mathrm{CI}$ ): plasma L-citrulline (190 $\mu \mathrm{M}, 84-297)$, plasma L-arginine (67 $\mu \mathrm{M}, 38-95)$, and plasma L-arginine/ADMA (ratio 117, 67-167). FeNO increased by $4.2 \mathrm{ppb}$ (1.7-6.7 ppb); ACQ decreased by -0.46 ( -0.67 to 0.27 points); the forced vital capacity and forced exhalation volume in 1 second, respectively, changed by $86 \mathrm{ml}(10-161 \mathrm{ml})$ and $52 \mathrm{ml}(-11$ to $132 \mathrm{ml})$. In a secondary analysis, the greatest $\mathrm{FEV}_{1}$ increments occurred in those subjects with late-onset asthma (>12 years) (63 $\mathrm{ml}$ [95\% Cl, 1-137]), in females (80 $\mathrm{ml}$ [95\% Cl, 5-154]), with a greater change seen in late-onset females $(100 \mathrm{ml}$, [95\% Cl, 2-177]). The changes in lung function or asthma control were not significantly associated with the changes before and after treatment in L-arginine/ADMA or FeNO.

CONCLUSION. Short-term L-citrulline treatment improved asthma control and FeNO levels in obese asthmatics with low or normal FeNO. Larger $\mathrm{FEV}_{1}$ increments were observed in those with lateonset asthma and in females.

TRIAL REGISTRATION. ClinicalTrials.gov NCT01715844.

FUNDING. NIH NHLBI R01 HL146542-01.

Conflict of interest: The authors have declared that no conflict of interest exists.

Copyright: (c) 2019, American Society for Clinical Investigation.

Submitted: July 11, 2019 Accepted: November 6, 2019 Published: December 19, 2019

Reference information: /CI Insight. 2019;4(24):e131733.

https://doi.org/10.1172/jici. insight.131733.

\section{Introduction}

Obesity contributes to the burden of asthma by reducing the response to inhaled corticosteroids (ICS), limiting disease control and quality of life, and increasing exacerbation frequency (1). Considering that $38.8 \%$ of asthmatics in the US are estimated to be obese, this constitutes a major public health problem (2). Unfortunately, there are limited options beyond weight loss to improve the health of these patients, begging the need to have additional therapeutic strategies. Obesity worsens inflammation in preexisting asthma and identifies a different clinical phenotype (3), which is characterized by late onset of asthma after childhood, a predominantly non-T2 type inflammatory process, and female sex. In these patients, BMI is often inversely 


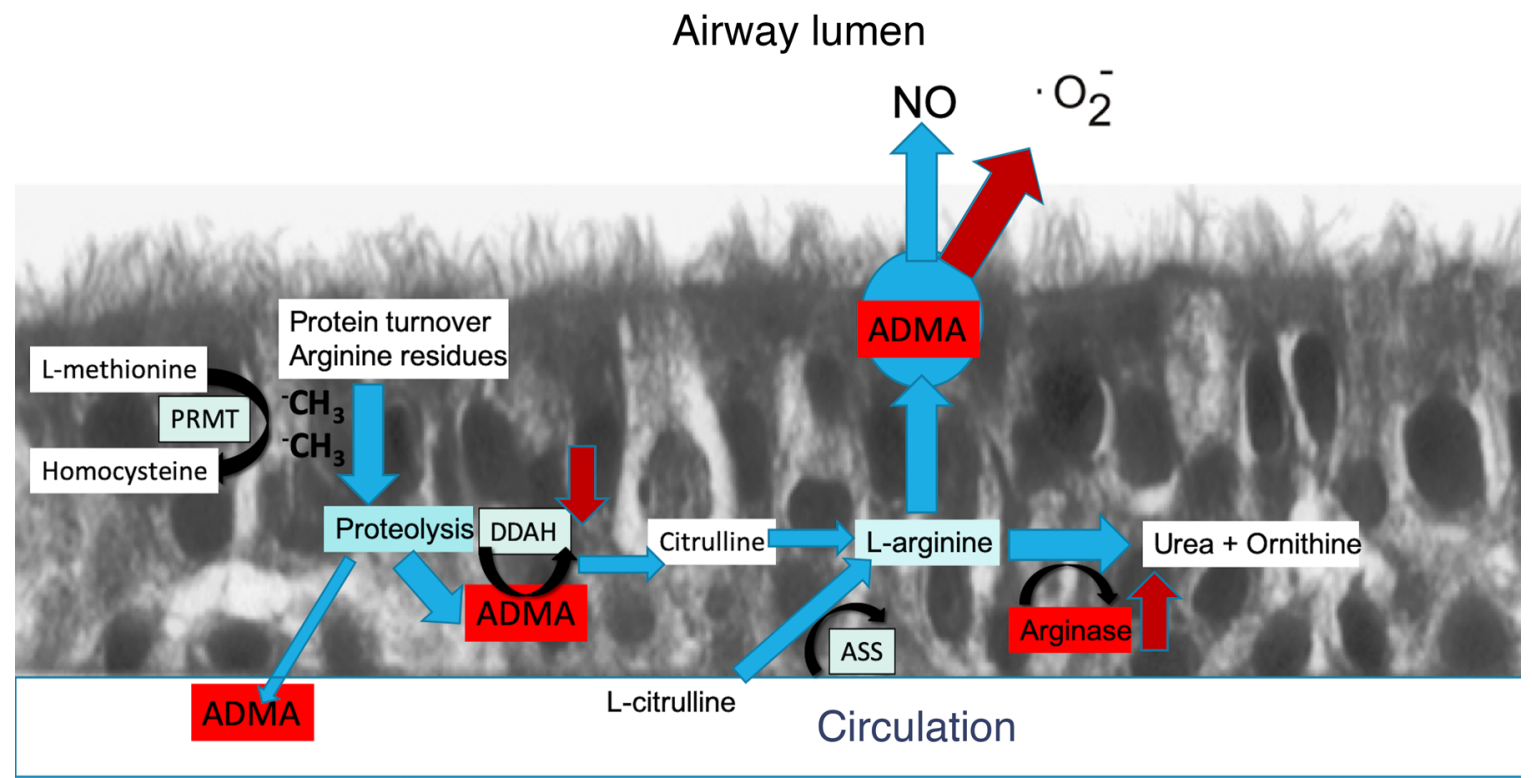

Figure 1. ADMA mediated NOS2 uncoupling in the airway epithelium. As part of normal protein catabolism, arginine residues in many proteins undergo posttranslational dimethylation by protein arginine $\mathrm{N}$-methyl transferases (PRMT), which use methyl groups donated from L-methionine. Subsequent proteolysis releases free asymmetric dimethyl arginine (ADMA), which can be either metabolized to L-citrulline and dimethylamine by dimethylarginine dimethylaminohydrolase (DDAH) or secreted into the circulation, where it is eventually excreted by the kidneys (48). Arginine succinate synthase (ASS) metabolizes L-citrulline to L-arginine, which can be used by NOS to generate NO. In addition, arginase competes with NOS to generate urea and ornithine from L-arginine. Given that increased oxidative stress is associated with reduced DDAH activity (48), and obesity as well as asthma have been associated with increased arginase activity (dark arrows), the combination of obesity and asthma can result in lowering L-arginine levels while increasing the concentration of ADMA. Having a low L-arginine to ADMA balance, favors NOS2 uncoupling. When this occurs, NOS2 preferentially produces anion superoxide instead of NO (gray arrows). Ultimately, this process may explain why some obese asthmatics have reduced NO airway bioavailability, with greater airway oxidative stress. Based on our previous findings showing that L-citrulline recouples airway epithelial NOS2, preventing these downstream events from occurring, we developed this pilot proof-of-concept study (5).

related to the fractional excretion of exhaled $\mathrm{NO}(\mathrm{FeNO})$ levels $(3,4)$. This can potentially occur via a metabolic imbalance characterized by lower L-arginine levels and higher concentrations of asymmetric dimethyl arginine (ADMA) (Figure 1 and ref. 5). Lower L-arginine/ADMA ratios favor airway epithelial inducible NO synthase (NOS2) uncoupling, promoting ROS formation at the expense of NO production. Ultimately this reduces airway NO bioavailability $(6,7)$, causing oxidative stress and potentially impairing the airway's ability to bronchodilate normally. This phenomenon may explain why lower L-arginine/ADMA ratios are associated with reduced lung function, more frequent respiratory symptoms, and lower asthma-related quality of life (8). In airway epithelial cells of obese asthmatics L-citrulline prevents many of the downstream effects associated with NOS2 uncoupling (5). Therefore, we hypothesized that in obese asthmatics with low or normal FeNO levels L-citrulline restores NO airway bioavailability, improving lung function and asthma control. To test this hypothesis, we conducted a feasibility proof-of-concept pilot study to (a) determine whether adding daily L-citrulline to maintenance asthma controller therapy would increase FeNO from baseline, while improving prebronchodilator forced exhalation volume in 1 second $\left(\mathrm{FEV}_{1}\right)$ and asthma control and (b) determine whether late- versus early-onset male or female asthma phenotypes have a differential response to L-citrulline supplementation.

\section{Results}

Study population. A total of 57 patients were screened for the study; 13 were screen failures due to reasons outlined in Figure 2. A total of 41 subjects were enrolled and completed the 2-week study. All 41 subjects took the L-citrulline daily throughout the study period (Figure 2). The characteristics of the study population are shown in Table 1 . The majority of participants were obese White females, with poorly controlled asthma; $30 \%$ met criteria for metabolic syndrome and approximately two-thirds of the study subjects had late-onset (diagnosis $>12$ years of age) asthma, with the average age of diagnosis being greater than 35 years. On average, subjects had mild-to-moderate obstruction on spirometry and a FeNO in the low-to-normal range of less than $25 \mathrm{ppb}$. The 


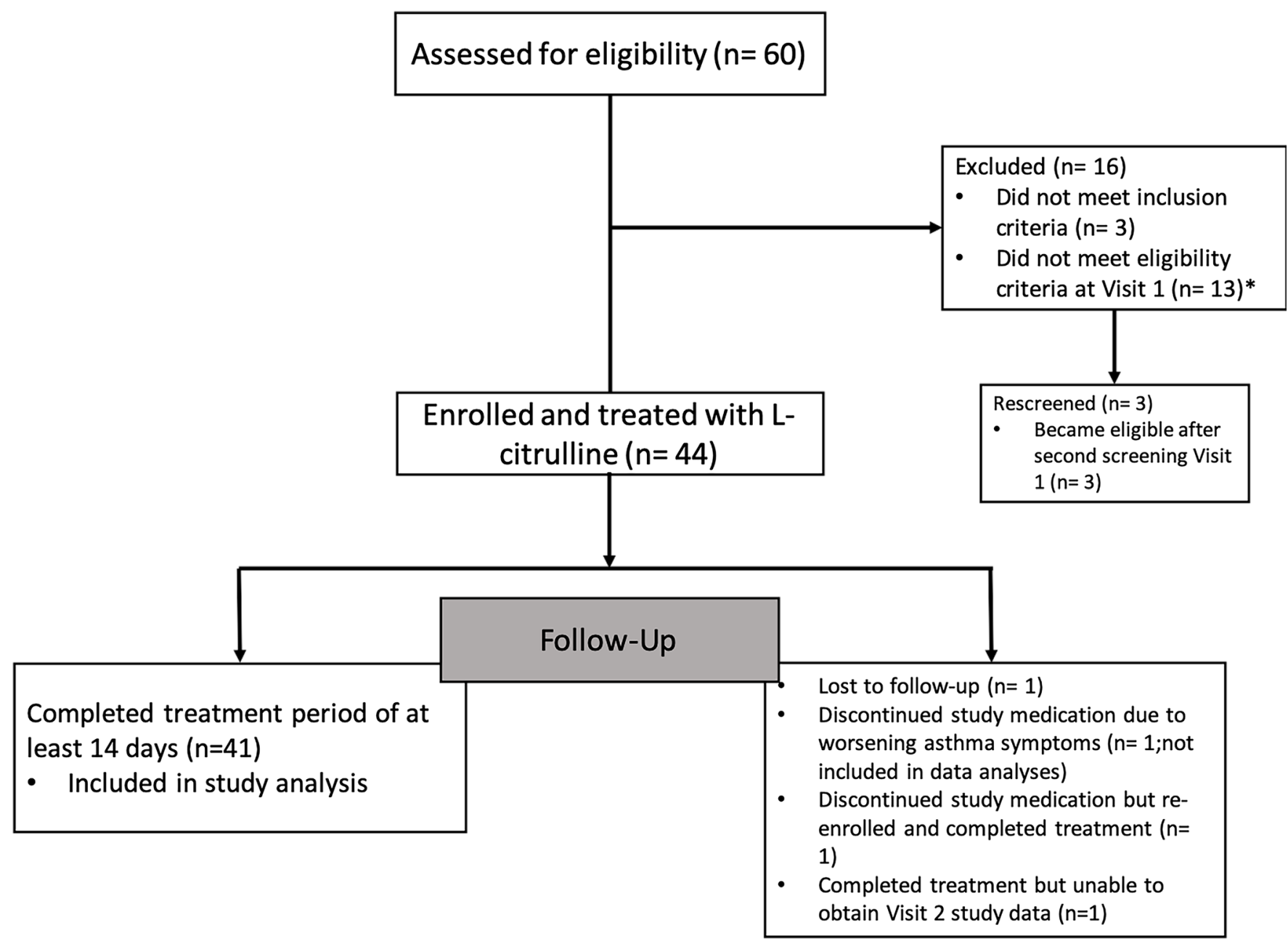

Figure 2. Consort diagram.

majority of subjects were on maintenance therapy with ICS/long-acting $\beta$ agonist (ICS/LABA) controllers.

Effect of L-citrulline supplementation on plasma levels of L-citrulline, L-arginine/ADMA, FeNO, asthma control questionnaire (ACQ) and lung function parameters (Table 2).

After treatment, L-citrulline plasma levels increased by nearly $800 \%$, while L-arginine levels rose by $116 \%$, L-arginine/ADMA levels rose by $90 \%$, and L-ornithine levels rose by $120 \%$. In contrast, ADMA, arginase, and products of L-ornithine metabolism, i.e., proline and the polyamines putrescine, spermine, and spermidine, did not significantly change. FeNO rose by an average of $4.2 \mathrm{ppb}(95 \% \mathrm{CI}, 1.8-6.7, P=0.001)$, and ACQ scores improved by an average decrease of 0.46 (95\% CI, $-0.64,-0.23, P=0.001)$ during the first week and by $-0.46(95 \% \mathrm{CI},-0.65,-0.27, P=0.001)$ at week 2 (Figure 3$)$. The effect on lung function was a marginal nonsignificant augmentation for $\mathrm{FEV}_{1}$ and a significant forced vital capacity (FVC) improvement.

Stratified analysis by age of asthma onset phenotype. To determine whether late-onset asthmatics differentially respond to L-citrulline, we performed a secondary analysis of the primary study outcomes stratified by the presence of early- or late-onset asthma, using 12 years of age as a cutoff. This age cutoff has previously been shown to adequately discriminate clinical and inflammatory differences across these phenotypes (9). Compared with the early-onset phenotype, the late-onset asthmatics had a greater improvement in $\mathrm{FEV}_{1}$ (Figure 4); whereas both early- and late-onset groups had similar improvements in asthma control (data not shown). In the late-onset asthmatics, L-citrulline significantly augmented FeNO (mean $\Delta 3.7 \mathrm{ppb}[95 \%$ CI, 0.85-6.6]), whereas it only marginally increased FeNO in the early-onset asthmatics $(P=0.052)$. In the subanalysis, females had a significant and greater improvement in $\mathrm{FEV}_{1}$ than males (Figure 4), while both groups showed improvements in asthma control. FeNO increased significantly among females (mean $\Delta 3.74$ ppb [95\% CI, 1-6.4]) but was not statistically significant in males $(P=0.09)$. As an exploratory analysis, 
Table 1. Baseline characteristics of the study population

\begin{tabular}{|c|c|}
\hline Median age (range) in yrs & $52(19-67)$ \\
\hline Sex (\% female) & $31(74)$ \\
\hline \multicolumn{2}{|l|}{ Race, median (\%) } \\
\hline White & $25(61)$ \\
\hline Black & $14(34)$ \\
\hline Other & $2(4)$ \\
\hline BMI, mean $(95 \% \mathrm{Cl})$ & $37(35-38)$ \\
\hline Systolic blood pressure $(\mathrm{mmHg})$, mean $(95 \% \mathrm{Cl})$ & $130(126-134)$ \\
\hline Diastolic blood pressure $(\mathrm{mmHg})$, mean $(95 \% \mathrm{Cl})$ & $82(79-84)$ \\
\hline Metabolic syndrome (\%) & $12(30 \%)$ \\
\hline Glucose (mg/dl), mean (95\% Cl) & $88(95 \% \mathrm{Cl}, 84-92)$ \\
\hline $\mathrm{HDL}(\mathrm{mg} / \mathrm{dl})$, mean $(95 \% \mathrm{Cl})^{\mathrm{A}}$ & $52(95 \% \mathrm{Cl}, 47-58)$ \\
\hline Triglycerides(mg/dl), mean $(95 \% \mathrm{Cl})$ & $101(95 \%$ Cl, 77-126) \\
\hline Abdominal girth (in.), mean (95\% Cl) & $44(95 \%$ Cl, 41-45) \\
\hline Age of asthma diagnosis, mean $(95 \% \mathrm{Cl})$ & 33 (27-39) \\
\hline Late onset, mean (\%) & $30(73)$ \\
\hline Early onset, mean (\%) & $11(27)$ \\
\hline ACQ, mean $(95 \% \mathrm{CI})$ & $1.5(1.2-1.8)$ \\
\hline ICS , mean (\%) & $14(34)$ \\
\hline ICS/LABA, mean (\%) & $30(73)$ \\
\hline ICS/LABA/LAMA, mean (\%) & $5(12)$ \\
\hline Leukotriene blockers, mean (\%) & $13(30)$ \\
\hline Anti-IL-5 mAb, mean (\%) & $3(7)$ \\
\hline FeNO (ppb), mean (95\% Cl) & $17(95 \% \mathrm{Cl}, 15-19)$ \\
\hline $\mathrm{FEV}_{1}(\mathrm{~L}) / \%$ predicted $(95 \% \mathrm{Cl})$ & $2.4(2.2-2.7) / 83$ (77-99) \\
\hline FVC (L)/\% predicted $(95 \% \mathrm{Cl})$ & $3.2(2.9-3.5) / 93$ (87-99) \\
\hline $\mathrm{FEV}_{1} / \mathrm{FVC}$, mean $(95 \% \mathrm{Cl})$ & $74(70-77)$ \\
\hline $\mathrm{FEV}_{1} \%$ postbronchodilator change, mean $(95 \% \mathrm{CI})$ & $8(5-14)$ \\
\hline \multicolumn{2}{|c|}{$\begin{array}{l}\text { Four participants took ICS in addition to ICS/LABA. Metabolic syndrome is defined as having at least } 3 \text { of the } 5 \\
\text { following criteria: (glucose }>100 \text {; triglycerides }>150 ; \mathrm{HDL}<40 \text {; hypertension }- \text { systolic } \geq 130 \text { or diastolic } \geq 80 \text {; abdominal } \\
\text { girth }>35 \text { inches for females or } 40 \text { inches for males). ACQ, asthma control questionnaire; ICS, inhaled corticosteroids; } \\
\text { LABA, long-acting } \beta \text { agonist; LAMA, long-acting muscarinic receptor antagonist; FeNO, fractional excretion of exhaled } \\
\text { NO; FEV }{ }_{1} \text {, forced exhalation volume in } 1 \text { second; FVC, forced vital capacity. }{ }^{A} H D L \text { values were only available from the } \\
\text { University of Colorado participants. } n=41 \text {. }\end{array}$} \\
\hline
\end{tabular}

we compared pre-FEV 1 in early- versus late-onset females and found that L-citrulline effects on $\mathrm{FEV}_{1}$ were greater in females with late-onset asthma (Figure 4).

Relationship between the $\triangle$ (before and after treatment) plasma L-arginine/ADMA, L-arginine/ornithine, L-citrulline, and the $\triangle F e N O, A C Q$, and $F E V_{1}$. After assessing normality, we examined the correlation between the $\triangle \mathrm{L}$-arginine/ADMA, L-arginine/ornithine ratios, and the $\triangle \mathrm{L}$-citrulline levels and the $\triangle \mathrm{FeNO}, \mathrm{ACQ}$, or $\mathrm{FEV}_{1}$. However, we did not observe any significant associations (Supplemental Table 1; supplemental material available online with this article; https://doi.org/10.1172/jci.insight.131733DS1).

Moreover, no associations were present between BMI and the $\Delta$ FeNO $(r=-0.27, P=0.08)$, ACQ $(r=$ $0.25, P=0.1)$, or $\mathrm{FEV}_{1}(r=0.008, P=0.9)$. BMI was, however, inversely associated with the $\Delta \mathrm{L}$-arginine/ ADMA ratio $(r=-0.42, P=0.008)$.

Safety. In general, L-citrulline was well tolerated (Table 3). Although the majority of patients experienced mild side effects, this did not lead to treatment discontinuation. Roughly $40 \%$ of patients complained of mild nausea or headache, which lasted fewer than 3 days, 20\% experienced lightheadedness with initial use of the medication, and $14 \%$ had diarrhea (defined as loose stool) lasting on average less than 2 days. L-Citrulline was associated with minimal and nonsignificant changes in blood pressure. Overall $(\Delta \mathrm{mmHg}$ mean $[95 \% \mathrm{CI}])$ changes in blood pressure were systolic ( -1.6 [-6.3 to 3.1]), diastolic (0.4 [ -0.3 to 4.5$])$, and mean arterial pressure $(-0.3[-4.2$ to 3.6$])$. 
Table 2. L-Citrulline changes before and after treatment in biomarkers and lung function parameters

\begin{tabular}{|c|c|c|c|c|}
\hline$n=38^{A}$ & Before & After & Mean difference $(95 \% \mathrm{CI})$ & $\boldsymbol{P}$ \\
\hline $\mathrm{FEV}_{1}(\mathrm{~L})$ (after) & $2.58(2.32-2.83)$ & $2.58(2.33-2.9)$ & $0.003(-0.05$ to 0.06$)$ & 0.9 \\
\hline FVC (L) (after) & $3.33(3.04-3.62)$ & $3.38(3.08-3.67)$ & $0.05(-0.03$ to 0.13$)$ & 0.2 \\
\hline $\mathrm{FEV}_{1} / \mathrm{FVC}$ (before) & 74.06 (70.57-77.56) & 74.10 (70.27-77.93) & $0.03(-1.3$ to 1.4$)$ & 0.9 \\
\hline L-citrulline, $\mu \mathrm{M}$ & $24(20-28)$ & $215(108-321)$ & $190(84-297)$ & $<0.001$ \\
\hline L-arginine/ADMA & $130(116-144)$ & 247 (198-296) & $117(67-167)$ & $<0.001$ \\
\hline Ornithine, $\mu \mathrm{M}$ & $47(41-53)$ & $104(79-130)$ & $57(34-80)$ & $<0.001$ \\
\hline Proline, $\mu \mathrm{M}$ & 183 (159-206) & $172(147-197)$ & -10 (-37 to 15$)$ & 0.4 \\
\hline Spermine, ng/ml & $42(34-50)$ & $39(30-48)$ & $-3(-5$ to 12$)$ & 0.3 \\
\hline Putrescine, $\mathrm{ng} / \mathrm{ml}$ & $36(26-45)$ & $44(25-63)$ & $8(8-25)$ & 0. \\
\hline
\end{tabular}

AThree patients failed to complete postsupplementation spirometry and were not included in the analysis. Before and after in the first column represent patients exposure to bronchodilator.

\section{Discussion}

In this proof-of-concept study of 41 obese poorly controlled asthmatics on ICS+LABA or long-acting muscarinic antagonists (LAMAs), 2-week treatment with $15 \mathrm{~g} / \mathrm{d}$ oral L-citrulline significantly increased the plasma L-arginine/ADMA ratios and FeNO levels, while improving asthma control, FVC, and marginally increasing $\mathrm{FEV}_{1}$. This study shows for the first time to our knowledge that increasing the L-arginine/ ADMA ratio, and thereby augmenting airway NO bioavailability, is a potential therapeutic strategy to improve the respiratory health of obese asthmatics with low or normal FeNO that are not adequately responding to standard asthma controller medications.

Supplementation with L-arginine has been shown to increase FeNO in children and adults in some studies (10) and to reduce airway inflammation and bronchial hyperresponsiveness in murine ovalbumin sensitization models (11-14). However, L-arginine supplementation as a therapeutic modality is limited, given its extensive first-pass metabolism in the liver and intestine (15). This is perhaps why one study found only modest improvements in $\mathrm{FEV}_{1}$ in asthmatic subjects after 1 week of L-arginine supplementation (16), and a different pilot study of 15 moderate-to-severe asthmatics failed to show significant increases in FeNO (10). As an alternative, L-citrulline is directly metabolized into L-arginine by airway epithelial cells (5) when L-arginine levels are low, as it can be seen in obese subjects or in patients with asthma. L-Citrulline is a nonessential amino acid that is essential to detoxify and remove ammonia from muscle and liver cells; it is not subjected to extensive first-pass metabolism by gut bacteria or liver arginases and can increase L-arginine levels in a dose-dependent manner (15). In addition to reducing epithelial NOS2 uncoupling and reducing nitrosative stress, L-citrulline may improve asthma control by increasing S-nitrosoglutathione (GSNO), the major source of NO bioactivity in the lung. We hypothesize that the extent to which L-citrulline is beneficial could depend on how much NO is produced and the extent of preservation of SNO-based signaling (17).

In patients with established asthma, obesity and weight gain have been associated with increased asthma severity. This is a major public health concern, given that the CDC has estimated that more than one-third of asthmatics are obese (2). Using the National Asthma Survey, we have previously shown that compared with lean asthmatic subjects, obese subjects with asthma are more likely to report continuous respiratory symptoms, experience a higher rate of nocturnal respiratory symptoms, and experience more asthma exacerbations requiring emergency room evaluation or hospitalization within the last 12 months than lean subjects with asthma (18). These results have been reproduced in several cross-sectional and longitudinal studies (1). Increasing BMI significantly reduces the efficacy of ICS or montelukast in achieving asthma control and reduces the effects of ICS on $\mathrm{FEV}_{1}$ (19-21). Moreover, among obese females with late-onset asthma with low FeNO, systemic steroids can even decrease lung function (22). It is unclear why ICS are less efficacious 


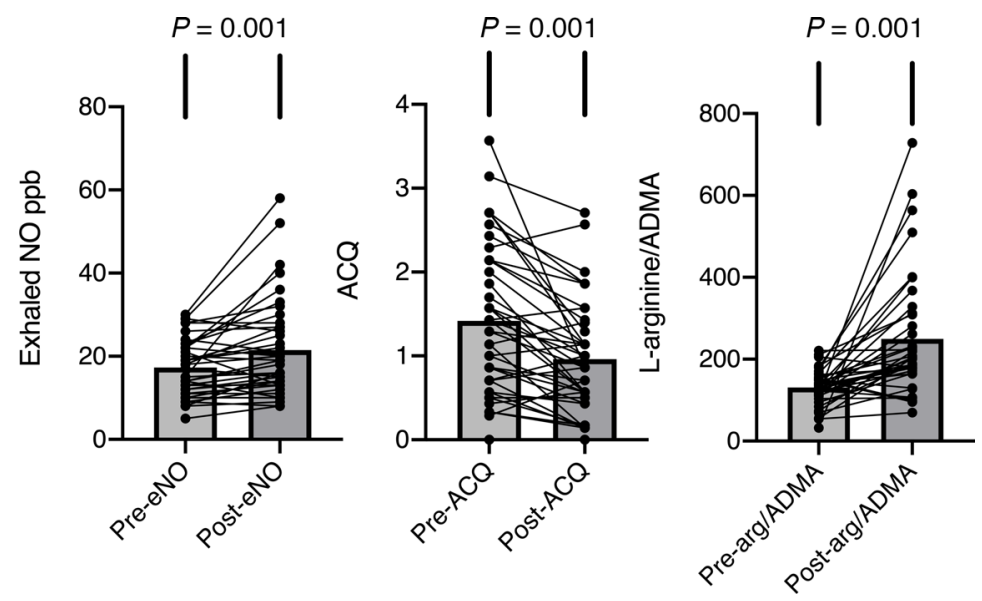

Figure 3. FeNO, ACQ, and plasma L-arginine/ADMA changes after a 2-week $15 \mathrm{~g} / \mathrm{d}$ treatment with L-citrulline supplementation. $n=41$. FeNO mean $\Delta 4.2 \mathrm{ppb}(95 \% \mathrm{Cl}, 1.7-6.7)$; ACQ mean $\Delta-0.46$ ( $95 \% \mathrm{Cl},-0.67$ to -0.27$)$; L-arginine/ADMA (ratio 117, 67-167).

in some obese asthmatics, but one potential explanation is that these patients have a less predominant T2 airway inflammatory phenotype. In fact, cluster analyses have shown that, in asthmatic subjects for whom BMI is an important discriminant factor, asthma is characterized as later onset (after childhood), with less atopy, lower eosinophil counts, and reduced FeNO levels (23-27). In addition, this phenotype is also characterized by having increased airway and systemic oxidative stress biomarkers $(26,28)$, which may be associated with increased corticosteroid resistance.

Regardless of body weight, airway concentrations of ADMA are greater in asthmatic adults and children when compared with controls, and L-arginine levels are lower in otherwise healthy obese and overweight subjects (29-32). Therefore, it is not surprising that the convergence of these 2 chronic diseases lowers the L-arginine/ADMA balance, uncoupling airway epithelial NOS (5). When this occurs, electrons flowing from the NOS nicotinamide adenine dinucleotide phosphate (NADPH) reductase domain to the oxygenase domain are diverted into molecular oxygen rather than to L-arginine (6). Several experimental studies have shown that this mechanism plays a role in asthma pathophysiology. Under uncoupling conditions, NOS generates superoxide, which correlates with increased airway oxidative stress in murine OVA models (33). In stimulated murine airway epithelial cells, Wells et al. observed that administration of ADMA reduces nitrite production while increasing superoxide levels in a dose-dependent manner (6). In addition, continuous ADMA infusion for 2 weeks increased airway resistance and reduced lung compliance in vivo in mice (7). This increased airway resistance was attributed to reduced NO bioavailability in the absence of increases in traditional biomarkers of allergic airway inflammation (7). Diet induced metabolic syndrome and obesity in mice increased airway ADMA and reduced L-arginine and NO levels, while causing oxidative and nitrosative stress and bronchial hyperresponsiveness in the absence of any airway inflammation $(34,35)$. Maternal exposure to high-fat diet causes similar L-arginine metabolic effects in the lungs of murine offspring (35). In primary human airway epithelial cells isolated from asthmatics stimulated with IL-13 and IFN- $\gamma$, ADMA has been shown to uncouple NOS2, reduce NO bioavailability, and increase oxidative stress (5). The Severe Asthma Research Program demonstrated the potential clinical relevance of this pathway by showing that BMI was inversely related to FeNO levels in late-onset asthmatics and that lower L-arginine/ADMA plasma ratios, which were lower in obese subjects, were associated with more frequent respiratory symptoms and reduced lung function (3). However, these results were only significant in those with late-onset asthma, suggesting that this pathway may be more relevant in this asthma phenotype (3). We have shown that treating primary airway epithelial cells with L-citrulline increases argininosuccinate, an enzyme that metabolizes L-citrulline to L-arginine, and halts ADMA-mediated NOS uncoupling, restoring NO metabolite levels and preventing oxidative and nitrosative stress (5). These results were the initial impetus leading to this proof-of-concept study.

The results of this pilot study are potentially paradigm shifting in how we think about NO in asthma. Its role as a biomarker for T2-related airway inflammation is well established; however, the role that NOS 


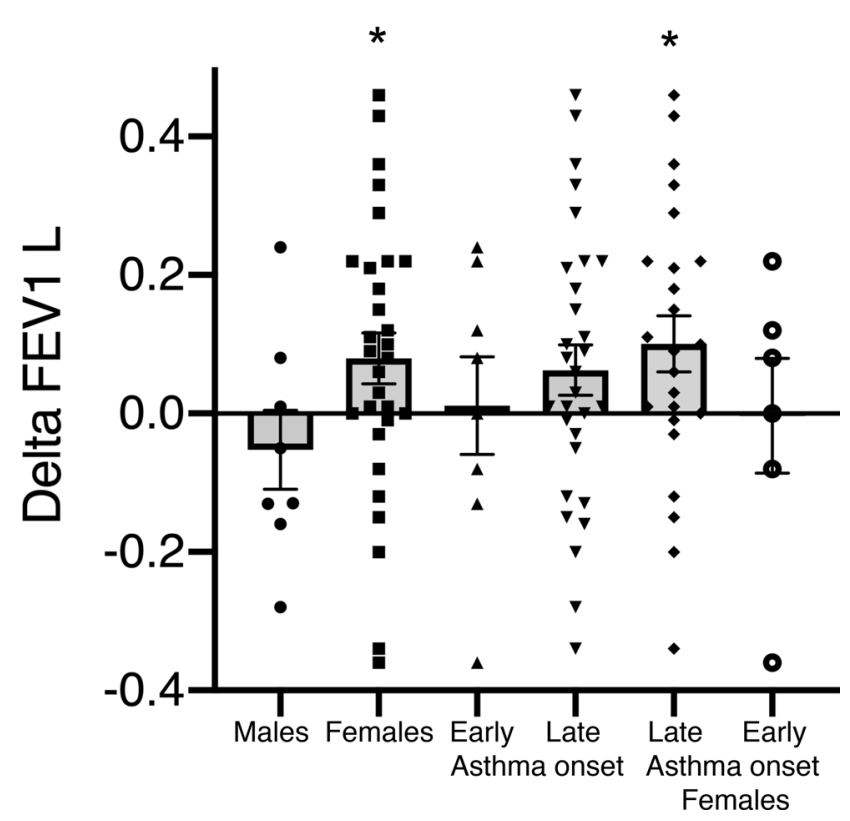

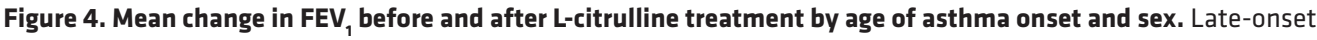
asthma females $=24$; early-onset females $=7 . \Delta$ (mean supplementation difference before and after L-citrulline treatment, $95 \% \mathrm{Cl})$ FEV early onset: $-11 \mathrm{ml}(-155$ to $17 ; P=0.8)$; FEV 1 late onset: $63 \mathrm{ml}(1-137, P=0.09)$; FEV females: $80 \mathrm{ml}$ (5-154; $P=0.03)$; FEV 1 males: $-52 \mathrm{ml}(-187$ to $8 ; P=0.3) ; \mathrm{FEV}_{1}$ female early onset: $-30(-21,200 ; P=0.9)$; FEV female late onset $100 \mathrm{ml}(16-184 ; P=0.02) .{ }^{*} P<0.05$.

products play in mediating physiological bronchodilation, and how this mechanism is disrupted in some asthma phenotypes, is largely unknown. Our results suggest that asthma control can improve while increasing FeNO in the absence of an asthma exacerbation. The fact that improvements occurred in patients on ICS+LABA and/or LAMA suggests the possibility of alternative pharmacological pathways that could be manipulated to improve respiratory health in patients with obese asthma or in those with low FeNO regardless of weight. One target in this pathway could potentially be arginase, an enzyme that is upregulated in asthma and reduces L-arginine availability for NOS (36). In the post hoc analyses, L-citrulline supplementation led to greater changes in prebronchodilator $\mathrm{FEV}_{1}$ among females and particularly those with late-onset disease. These results potentially suggest that treatment with L-citrulline could potentially be beneficial for this clinical asthma phenotype.

Importantly, although this short-term supplementation of L-citrulline did not change ADMA levels, it did increase L-ornithine, the product of arginase activity. However, there was no increase seen in circulating concentrations of proline or polyamines, both products of L-ornithine metabolism. Larger clinical studies will determine the clinical relevance of these findings for airway biology and function. There are important limitations to this study. This was a short-term, open-labeled intervention, and thus longer, placebo-controlled L-citrulline studies are needed to further validate our findings. While we saw a preferential response to L-citrulline-induced lung function changes in $\mathrm{FEV}_{1}$ among female participants with late-onset asthma, the lack of effect on other subgroups could be secondary to a type II error from having smaller number of study subjects. There is a possibility of bias in the results owing to the regression to the mean effect, since subjects measured for a second visit were screened by their FeNO value in the first visit $(37,38)$. However, the potential for this bias is small, given that usually there is a high within-subject correlation of FeNO measurements (39). We were not able to show that either plasma L-arginine/ ADMA nor the L-citrulline $\Delta$ levels were significantly associated with the study outcomes, which could be in part be explained by having biological mechanisms not directly explained by the changes on these biomarkers. While we have designed this intervention for obese asthmatics, the fact that BMI was not associated with any of the clinical primary study outcomes could suggest the possibility that L-citrulline is not necessarily specific for obese asthmatics but rather a treatment that could be effective in asthmatic subjects with low or normal FeNO phenotypes, regardless of body weight. 
Table 3. Side effects

\begin{tabular}{|c|c|c|}
\hline & $n=41$ & Average duration (d) \\
\hline \multicolumn{3}{|l|}{ Nausea } \\
\hline Mild & $41 \%$ & 2.7 \\
\hline Moderate & $15 \%$ & 1.7 \\
\hline Severe & $12 \%$ & 3.0 \\
\hline \multicolumn{3}{|l|}{ Headache } \\
\hline Mild & $44 \%$ & 3.3 \\
\hline Moderate & $27 \%$ & 2.4 \\
\hline Severe & $17 \%$ & 3.0 \\
\hline \multicolumn{3}{|c|}{ Lightheadedness } \\
\hline Mild & $20 \%$ & 2.5 \\
\hline Moderate & $12 \%$ & 2.0 \\
\hline Severe & $3 \%$ & 2.0 \\
\hline Diarrhea & $12 \%$ & 1.6 \\
\hline
\end{tabular}

\section{Methods}

Study population. We conducted a phase II proof-of-concept study (ClinicalTrials.gov NCT01715844) to determine the feasibility and safety of oral L-citrulline in obese asthmatics. Patients were recruited at Duke University Health System and the University of Colorado Medical Center. Inclusion criteria included age $>18$ and $<66$ years, having a physician diagnosis of asthma, BMI $\geq 30$, FeNO $\leq 30$, and treatment with ICS with or without concomitant LABAs or LAMAs. Patients were excluded if they met any of the following criteria: active smoking in the preceding year, $>10$ pack/yr smoking history, serum creatinine $>2.0$, current statin use, ICS dose $>1000 \mu \mathrm{g}$ fluticasone or equivalent, requirement for systemic corticosteroids or presence of an asthma exacerbation within 4 weeks of enrollment, and a positive pregnancy test.

Study design. Patients who met inclusion and exclusion criteria were treated with open-label $15 \mathrm{~g} / \mathrm{d}$ L-citrulline (Hiebers) in Durham, North Carolina, USA, or Denver, Colorado, USA, for 15 days. Although a dose of $6 \mathrm{~g} / \mathrm{d}$ L-citrulline is sufficient to effectively and safely raise the plasma L-arginine and the L-arginine/ADMA ratio in nonobese healthy subjects (15), the appropriate dose in obese asthmatics, who are known to have higher arginase levels and lower L-arginine/ADMA ratios, is unknown $(40,41)$. The study dose was chosen based on the fact that at doses higher than $15 \mathrm{~g}$, the renal conversion of L-citrulline to L-arginine is fully saturated and, therefore, using higher doses would not necessarily translate into higher L-arginine levels (42); a dose of $>15 \mathrm{~g} / \mathrm{d}$ L-citrulline could impose a theoretical risk of inducing an osmotic diarrhea (43). At the baseline visit, patients underwent weight and height determinations, pre- and post-albuterol spirometry (Care Fusion), and FeNO testing (Niox Vero) following the American Thoracic Society's standards. Degree of asthma control was assessed using the Juniper ACQ (44-46). Plasma samples were obtained by venipuncture before and after treatment and frozen at $-80^{\circ} \mathrm{C}$ prior to shipment on dry ice to the Hospital for Sick Children, where liquid chromatography-mass spectrometry was used to quantify L-arginine, L-citrulline, L-ornithine, ADMA, polyamines, and proline levels, as previously described (47). Arginase concentration was measured by commercial ELISA (catalog RAB1271) (MilliporeSigma). After the first week of treatment, patients were contacted by phone to ascertain ACQ scores. All baseline procedures were repeated at the completion of treatment. Adherence was determined by daily intake questionnaire and by counting the number of empty L-citrulline packages at the completion of the study.

Statistics. Using a convenient sample, we determined the differences between values before and after L-citrulline treatment for the following study outcomes: (a) FeNO (primary), (b) plasma L-arginine/ ADMA and ACQ (secondary), and (c) exploratory endpoints (i.e., lung function [prebronchodilator FEV ${ }_{1}$, $\mathrm{FVC}$, and $\left.\mathrm{FEV}_{1} / \mathrm{FVC}\right]$; plasma levels of L-citrulline, ADMA, ornithine and proline; and arginase concentration). The paired 2-tailed $t$ test for normally distributed data and sign-rank test for nonparametric matched distributions were used to determine the statistical significance of the changes before and after treatment in the study outcomes. Additional analyses included (a) the Pearson's correlation between the changes in L-arginine/ADMA, ornithine, L-arginine/ornithine, and FeNO, with the changes in asthma control and lung function, and (b) the changes before and after treatment in study outcomes between the 
early and late-onset asthma male and female phenotypes. As an additional exploratory analysis, we evaluated whether the baseline BMI correlated with any of the primary outcome measures. $P<0.05$ was considered statistically significance. All statistical analyses were performed using Stata 14.0.

Study approval. Patients provided written, informed consent. Studies were performed with the approval of the Duke University Health System and the University of Colorado Medical Center IRBs.

\section{Author contributions}

FH, HG, SS, DW, TJS, and LGQ prepared the manuscript. FH, SS, KW, VS, MHC, NP, EC, TJS, and LGQ were responsible for subject recruitment and clinical evaluation. FH and LGQ performed statistical analysis. HG and DW were responsible for laboratory analysis.

\section{Acknowledgments}

This study was funded in part by NIH NHLBI grant R01 HL146542-01.

Address correspondence to: Fernando Holguin, Department of Medicine, University of Colorado School of Medicine, 12700 East 19th Avenue 9C03, Aurora, Colorado 80045, USA. Phone: 303.724.6095; Email: fernando.holguin@ucdenver.edu.

1. Dixon AE, et al. An official American Thoracic Society Workshop report: obesity and asthma. Proc Am Thorac Soc. 2010;7(5):325-335.

2. CDC. Asthma and Obesity. http://www.cdc.gov/asthma/asthma_stats/asthma_obesity.htm. Updated August 9, 2013. Accessed November 20, 2019

3. Holguin F, et al. An association between L-arginine/asymmetric dimethyl arginine balance, obesity, and the age of asthma onset phenotype. Am J Respir Crit Care Med. 2013;187(2):153-159.

4. Moore WC, et al. Identification of asthma phenotypes using cluster analysis in the Severe Asthma Research Program. Am $J$ Respir Crit Care Med. 2010;181(4):315-323.

5. Winnica D, et al. 1-Citrulline prevents asymmetric dimethylarginine-mediated reductions in nitric oxide and nitrosative stress in primary human airway epithelial cells. Clin Exp Allergy. 2017;47(2):190-199.

6. Wells SM, Holian A. Asymmetric dimethylarginine induces oxidative and nitrosative stress in murine lung epithelial cells. Am $J$ Respir Cell Mol Biol. 2007;36(5):520-528.

7. Wells SM, Buford MC, Migliaccio CT, Holian A. Elevated asymmetric dimethylarginine alters lung function and induces collagen deposition in mice. Am J Respir Cell Mol Biol. 2009;40(2):179-188.

8. Holguin F, Khatri S, Serpil E, Powers RW, Trudeau J, Wenzel SE. Reduced L-arginine/ADMA as a potential mechanism to explain increased symptom severity and reduced atopy in late onset obese asthmatics. Am J Respit Crit Care Med. 2012;185:A2197.

9. Miranda C, Busacker A, Balzar S, Trudeau J, Wenzel SE. Distinguishing severe asthma phenotypes: role of age at onset and eosinophilic inflammation. J Allergy Clin Immunol. 2004;113(1):101-108.

10. Kenyon NJ, Last M, Bratt JM, Kwan VW, O’Roark E, Linderholm A. 1-Arginine supplementation and metabolism in asthma. Pharmaceuticals (Basel). 2011;4(1):187-201.

11. Abuzayan I, Turner SW. Changes in exhaled nitric oxide after ingestion of L-arginine in children: a pilot study. Pediatr Pulmonol. 2010;45(3):236-240.

12. Mabalirajan U, et al. Beneficial effects of high dose of L-arginine on airway hyperresponsiveness and airway inflammation in a murine model of asthma. J Allergy Clin Immunol. 2010;125(3):626-635.

13. Kharitonov SA, Lubec G, Lubec B, Hjelm M, Barnes PJ. L-arginine increases exhaled nitric oxide in normal human subjects. Clin Sci. 1995;88(2):135-139.

14. Mansoor JK, et al. L-arginine supplementation enhances exhaled NO, breath condensate VEGF, and headache at 4,342 m. High Alt Med Biol. 2005;6(4):289-300.

15. Schwedhelm E, et al. Pharmacokinetic and pharmacodynamic properties of oral L-citrulline and L-arginine: impact on nitric oxide metabolism. Br J Clin Pharmacol. 2008;65(1):51-59.

16. de Gouw HW, Verbruggen MB, Twiss IM, Sterk PJ. Effect of oral L-arginine on airway hyperresponsiveness to histamine in asthma. Thorax. 1999;54(11):1033-1035.

17. Gaston B, et al. Relaxation of human bronchial smooth muscle by S-nitrosothiols in vitro. J Pharmacol Exp Ther. 1994;268(2):978-984.

18. Taylor B, Mannino D, Brown C, Crocker D, Twum-Baah N, Holguin F. Body mass index and asthma severity in the National Asthma Survey. Thorax. 2008;63(1):14-20.

19. Peters-Golden M, Swern A, Bird SS, Hustad CM, Grant E, Edelman JM. Influence of body mass index on the response to asthma controller agents. Eur Respir J. 2006;27(3):495-503.

20. Saint-Pierre P, Bourdin A, Chanez P, Daures JP, Godard P. Are overweight asthmatics more difficult to control? Allergy. 2006;61(1):79-84.

21. Camargo CA, et al. Body mass index and response to asthma therapy: fluticasone propionate/salmeterol versus montelukast. J Asthma. 2010;47(1):76-82.

22. Wu W, et al. Multiview cluster analysis identifies variable corticosteroid response phenotypes in severe asthma. Am J Respir Crit 
Care Med. 2019;199(11):1358-1367.

23. Moore WC, et al. Identification of asthma phenotypes using cluster analysis in the Severe Asthma Research Program. Am J Respir Crit Care Med. 2010;181(4):315-323.

24. Haldar P, et al. Cluster analysis and clinical asthma phenotypes. Am J Respir Crit Care Med. 2008;178(3):218-224.

25. Todd DC, Armstrong S, D'Silva L, Allen CJ, Hargreave FE, Parameswaran K. Effect of obesity on airway inflammation: a cross-sectional analysis of body mass index and sputum cell counts. Clin Exp Allergy. 2007;37(7):1049-1054

26. Komakula S, et al. Body mass index is associated with reduced exhaled nitric oxide and higher exhaled 8-isoprostanes in asthmatics. Respir Res. 2007;8:32

27. Sutherland TJ, Sears MR, McLachlan CR, Poulton R, Hancox RJ. Leptin, adiponectin, and asthma: findings from a population-based cohort study. Ann Allergy Asthma Immunol. 2009;103(2):101-107.

28. Holguin F, Fitzpatrick A. Obesity, asthma, and oxidative stress. J Appl Physiol. 2010;108(3):754-759.

29. Scott JA, et al. Asymmetric dimethylarginine is increased in asthma. Am J Respir Crit Care Med. 2011;184(7):779-785.

30. Carraro S, et al. Asymmetric dimethylarginine in exhaled breath condensate and serum of children with asthma. Chest. 2013;144(2):405-410.

31. Eid HM, Arnesen H, Hjerkinn EM, Lyberg T, Seljeflot I. Relationship between obesity, smoking, and the endogenous nitric oxide synthase inhibitor, asymmetric dimethylarginine. Metab Clin Exp. 2004;53(12):1574-1579.

32. Ito T, et al. Early obesity leads to increases in hepatic arginase I and related systemic changes in nitric oxide and L-arginine metabolism in mice. J Physiol Biochem. 2018;74(1):9-16.

33. Ahmad T, Mabalirajan U, Ghosh B, Agrawal A. Altered asymmetric dimethyl arginine metabolism in allergically inflamed mouse lungs. Am J Respir Cell Mol Biol. 2010;42(1):3-8.

34. Singh VP, et al. Metabolic syndrome is associated with increased oxo-nitrative stress and asthma-like changes in lungs. PLoS ONE. 2015;10(6):e0129850.

35. Grasemann C, Herrmann R, Starschinova J, Gertsen M, Palmert MR, Grasemann H. Effects of fetal exposure to high-fat diet or maternal hyperglycemia on L-arginine and nitric oxide metabolism in lung. Nutr Diabetes. 2017;7(2):e244.

36. van den Berg MP, Meurs H, Gosens R. Targeting arginase and nitric oxide metabolism in chronic airway diseases and their co-morbidities. Curr Opin Pharmacol. 2018;40:126-133.

37. Molino A, et al. Comparison of three different exhaled nitric oxide analyzers in chronic respiratory disorders. $J$ Breath Res. 2019;13(2):021002.

38. Gill M, Graff GR, Adler AJ, Dweik RA. Validation study of fractional exhaled nitric oxide measurements using a handheld monitoring device. J Asthma. 2006;43(10):731-734

39. Mee RW, Chua TC. Regression toward the mean and the paired sample t test. The American Statistician. 1991;45(1):39-42.

40. Morris CR, Poljakovic M, Lavrisha L, Machado L, Kuypers FA, Morris SM. Decreased arginine bioavailability and increased serum arginase activity in asthma. Am J Respir Crit Care Med. 2004;170(2):148-153

41. Holguin F, et al. An association between L-arginine/asymmetric dimethyl arginine balance, obesity, and the age of asthma onset phenotype. Am J Respir Crit Care Med. 2013;187(2):153-159.

42. Moinard C, Nicolis I, Neveux N, Darquy S, Bénazeth S, Cynober L. Dose-ranging effects of citrulline administration on plasma amino acids and hormonal patterns in healthy subjects: the Citrudose pharmacokinetic study. Br J Nutr. 2008;99(4):855-862

43. Grimble GK. Adverse gastrointestinal effects of arginine and related amino acids. J Nutr. 2007;137(6 Supp1 2):1693S-1701S

44. American Thoracic Society, European Respiratory Society. ATS/ERS recommendations for standardized procedures for the online and offline measurement of exhaled lower respiratory nitric oxide and nasal nitric oxide, 2005. Am J Respir Crit Care Med. 2005;171(8):912-930.

45. Gardner RM, Hankinson JL. Standardization of spirometry--1987 ATS update (American Thoracic Society). J Occup Med. 1988;30(3):272-273.

46. Juniper EF, O'Byrne PM, Guyatt GH, Ferrie PJ, King DR. Development and validation of a questionnaire to measure asthma control. Eur Respir J. 1999;14(4):902-907.

47. Scott JA, et al. Asymmetric dimethylarginine is increased in asthma. Am J Respir Crit Care Med. 2011;184(7):779-785.

48. Teerlink T. ADMA metabolism and clearance. Vasc Med. 2005;10 Suppl 1:S73-S81. 